\title{
Evaluation of irradiation hardening and microstructure evolution under the synergistic interaction of He and subsequent Fe ions irradiation in CLAM steel
}

\author{
Y.P. Wei, P.P. Liu Y.M. Zhu, Z.Q. Wang, F.R. Wan, Q. Zhan* \\ School of Materials Science and Engineering, University of Science and Technology \\ Beijing, Beijing 100083, China
}

\begin{abstract}
Sequential dual-ion irradiation is a useful technique for experimental exploration on the synergistic effects of ion accumulation and cascade damage. In this research, the helium-ion accumulation concomitant with displacement damage induced by helium and iron ions irradiation in China low active martensitic (CLAM) steel was studied by ion-irradiation, transmission electron microscopy and nano-indentation technique. The helium bubbles formed under continuous implantation of helium ions at room temperature and the helium dose forming observed bubbles resolved by TEM clearly in CLAM steel is around $0.7 \times 10^{17}$ $1.0 \times 10^{17} \mathrm{He}^{+} / \mathrm{cm}^{2}$ under single $100 \mathrm{keV} \mathrm{He}^{+}$irradiation. Significant irradiation hardening was observed in the samples with various ion- and dose- irradiations. Positive correlation between the hardening increment and the helium-ion dose has been established in single helium-ion irradiated samples. On the other hand, the subsequent Fe-ion irradiation greatly promoted the formation and growth of helium bubbles as well as dislocation loops in sequential dual-ion irradiated samples. No significant contribution of the subsequent Fe-ion irradiation on the hardness increment was found for the Sequential dual-ion irradiated samples. It is suggested that the defects recombination, the combination effects of size and density of defects contribute to the degree of irradiation hardening. The calculated hardness increment based on dispersion strengthening model and the experimental microstructure analysis followed the same trend as the experimental nano-indentation data.
\end{abstract}

Keywords: Irradiation hardening, Microstructure, Ion-irradiation, Nano-indentation, 
Transmission electron microscopy, CLAM steel

* Corresponding author: qzhan@mater.ustb.edu.cn (Q. Zhan)

\section{Introduction}

Reduced activation Ferritic / Martensitic steels (RAFM steels ) are considered as one of the potential candidate structural materials for the demonstration (DEMO) fusion power plant because of their excellent swelling resistance and low activation under neutron irradiation ${ }^{[1]}$. The mechanical properties stability of materials under irradiation environment is very important in determining the commercial viability for a fusion reactor. Neutrons with high energy of $14 \mathrm{MeV}$ may cause serious irradiation damage accompanied by the formation of huge amounts of hydrogen and helium due to nuclear transmutation reactions. Helium, being a particular problem, has an extremely low solubility in metals (approximately parts per billion level) and can easily accumulate to form helium bubbles leading to irradiation swelling and the increase of ductile to brittle transition temperature (DBTT ${ }^{[2,3]}$. Note that DBTT shift increases with the increasing irradiation hardening and thus a reduction of hardening is effective to reduce the DBTT shift ${ }^{[4]}$. The synergistic effect of displacement cascade damage and helium accumulation may aggravate microstructure evolution as well as irradiation hardening, which deserves detailed investigation.

Sequential dual-ion irradiation is a useful technique for experimental exploration on the synergistic effects of two kinds of ion irradiation ${ }^{[5]}$. Heavy ion irradiation is frequently used to simulate the effects of neutron damage due to their high damage rate and rare radioactive products ${ }^{[6,7]}$. Helium ion implantation is often used to investigate the diffusion of helium atoms and the nucleation of helium bubbles. However unlike neutrons, the electronic stopping limits the range of ion into a solid. Typical low energy helium beam or MeV Fe-ions damaged layers only have a shallow depth below the irradiated sample surface ${ }^{[8]}$, which cannot be analyzed with standard mechanical tests. Nano-indentation testing technique has been proved successfully in extracting the properties of bulk material from small-scale tests. Many related 
experiments ${ }^{[9]}$ have been performed effectively to directly measure the hardness from ion-irradiated surface of material using the continuous stiffness measurement (CSM) mode ${ }^{[10]}$, through which the hardness-depth profile can be obtained continuously only by a single indent. Bulk-equivalent irradiation hardness can then be determined by converting the experimental nanoindentaiton data using developed computation models, such as the widespread Nix-Gao model ${ }^{[11]}$, Kasada method ${ }^{[12]}$ and Korsunsky model ${ }^{[13]}$.

In the present work, we choose China Low Activation Martensitic (CLAM) steel, one of RAFM steels, as the model system. Recently, much of the study of the irradiation effects in CLAM steel was driven. It was found that the density of dislocation loops induced by ion-irradiation could be decreased due to the existence of fine carbide precipitates with high density, resulting in the $\sim 23.7 \%$ decrease of irradiation hardening ratio in CLAM stee ${ }^{[14]}$. In the tensile results, the total elongation is $\sim 2.2 \%$ and $\sim 8 \%$ for samples irradiated with 1499 appm and 658 appm helium ions, respectively. The results revealed that helium concentration has a strong effect on the deformation behavior ${ }^{[15]}$. When CLAM steel was underwent the neutron irradiation to $1.25 \mathrm{dpa}$ at $470 \square$, the yield stress (YS) was increased $\sim 150 \mathrm{MPa}$ tested at room temperature and ductile to brittle transition temperature (DBTT) was increased

$\sim 10^{\circ} \mathrm{C}^{[16]}$. Helium- as well as iron-ion irradiations, nano-indentation test and the corresponding microstructure analysis were performed to investigate the synergistic effects of helium accumulation and iron-ion irradiation cascade damage on the mechanical property. The results are expected to be able to help deepen the understanding on the effect of the helium built up in materials and the relationship between microstructure evolution and the irradiation hardening.

\section{Experimental procedure}

The CLAM steel was heat-treated by normalizing at $1263 \mathrm{~K}$ for $30 \mathrm{~min}$ and was fully martensitic after water quenching at room temperature. The tempering was conducted at $1023 \mathrm{~K}$ for $90 \mathrm{~min}$. The chemical composition of the steel is given in 
Table 1. Bulk specimens were cut out by wire electrode discharge machining for ion irradiation and nano-indentation (NI) test. The surface of the specimens was mechanically polished carefully by diamond polishing paste. Finally, the plates were annealed at $700{ }^{\circ} \mathrm{C}$ for 30 minutes in vacuum quartz tube to reduce the influence of residual stress on the NI test results. At the same time, TEM specimens with $3 \mathrm{~mm}$ in diameter were punched out and then polished by twin-jet electro-polisher using a $5 \% \mathrm{HClO}_{4}-95 \% \mathrm{C}_{2} \mathrm{H}_{5} \mathrm{OH}$ polishing solution.

Table1. Chemical composition of CLAM steel in wt\%.

\begin{tabular}{lllllllll}
\hline Material & Fe & C & Mn & W & V & Ta & Cr & Si \\
\hline CLAM & Bal. & 0.091 & 0.47 & 1.45 & 0.20 & 0.05 & 8.93 & 0.036 \\
\hline
\end{tabular}

Ion irradiation was then performed at a terminal chamber of the electron cyclotron resonance source $320 \mathrm{kV}$ high-voltage platform in Lanzhou Institute of Modern Physics, Chinese Academy of Sciences. The specimens were mounted on a copper holder with good heat conductivity. All implantations were performed at room temperature. The temperature of specimens during ion irradiation was at ambient temperature. Single $100 \mathrm{keV} \mathrm{He}{ }^{+}$was implanted into the samples with the dose of $0.7 \times 10^{17}, 1.0 \times 10^{17}, 1.7 \times 10^{17}-$ ion $/ \mathrm{cm}^{2}$, respectively. Subsequently, some pre-He implanted specimens were bombarded by Fe-ions to $5.0 \times 10^{15} \mathrm{Fe}^{11+} / \mathrm{cm}^{2}$ at $950 \mathrm{keV}$ chosen to be able to overlap the He-induced damage profile and Helium content profile. At the same time, single $\mathrm{Fe}^{11+}$ irradiation with the dose of $5.0 \times 10^{15}$ ions $/ \mathrm{cm}^{2}$ was also carried out to study the individual contributions of displacement damage on the microstructural and hardness changes. The detailed irradiation parameters are given in Table 2.

Table 2 specific irradiation conditions for samples

\begin{tabular}{|c|c|c|c|c|c|c|c|}
\hline & $1 \#$ & $2 \#$ & $3 \#$ & $4 \#$ & $5 \#$ & $6 \#$ & $7 \#$ \\
\hline Step1: $10^{17} \mathrm{He}^{+} / \mathrm{cm}^{2} *$ & 0.7 & 1.0 & 1.7 & 0.7 & 1.0 & 1.7 & - \\
\hline Step2: $10^{15} \mathrm{Fe}^{11+} / \mathrm{cm}^{2}$ & - & - & - & 5.0 & 5.0 & 5.0 & 5.0 \\
\hline
\end{tabular}

*) here the energy for $\mathrm{He}^{+}$and $\mathrm{Fe}^{11+}$ are $100 \mathrm{keV}$ and $950 \mathrm{keV}$ respectively

The depth distribution profile of helium atoms and dpa (displacement per atom) under a serious of irradiation conditions in CLAM steel was calculated by Monte-Carlo SRIM 2008 code $^{[8,17]}$. Note that the dpa peaks along the implantation depth are around $300 \mathrm{~nm}$ for various irradiation conditions in the present study as 
shown in Fig.1.

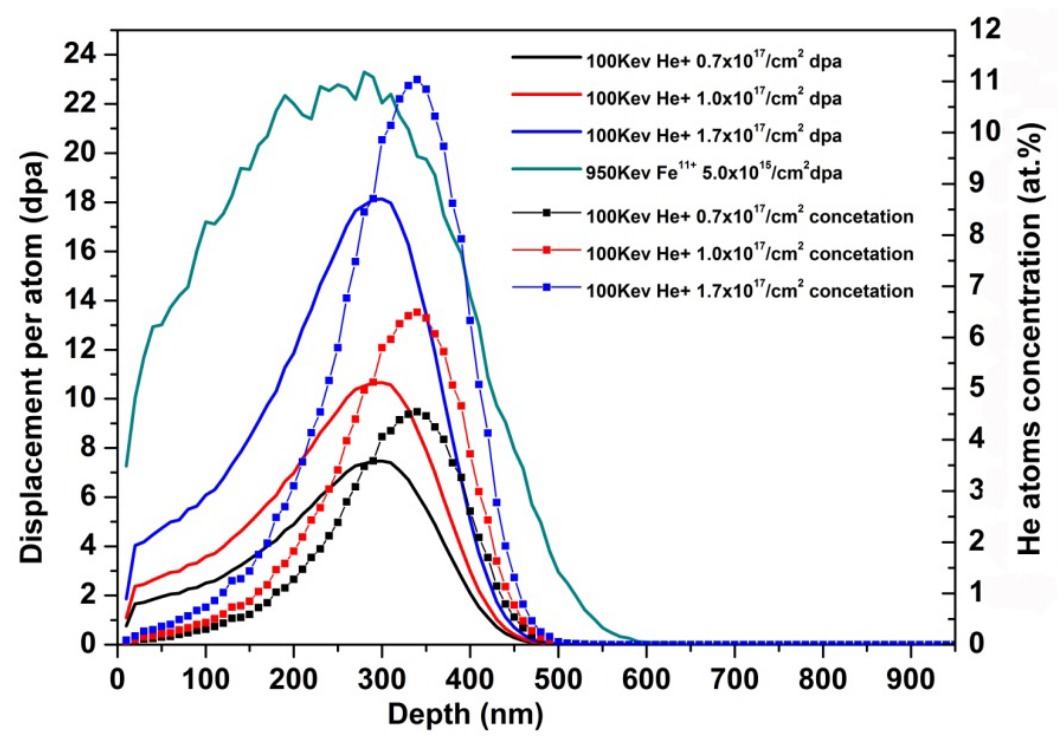

Fig. 1 Depth profile of the dpa and Helium atoms concentration for each irradiation condition (Calculated by SRIM 2008 code).

The mechanical properties of the bulk samples were characterized using Nano indenter XP (Agilent Corp.) with a Berkovich indenter tip. All the tests were operated using the CSM (continuous stiffness measurement) mode and a constant nominal strain rate of $0.05 \mathrm{~s}^{-1}$ was adopted. The total depth of penetration was $\sim 1000 \mathrm{~nm}$. For each sample six indentations were taken to obtain the average NI-hardness as a function of depth was obtained. Un-irradiated CLAM steel microstructure has been analysis in previous experiments ${ }^{[14]}$. The microstructure investigation was carried out using an FEI Tecnai- F20 transmission electron microscope operated at $200 \mathrm{kV}$.

\section{Results and discussion}

Fig. 2 gives NI hardness versus depth in CLAM steel before and after irradiation. Indentation Size Effect (ISE) was observed for all the specimens, behaving as that the measured hardness decreased with the increase of indentation depth at $h>30 \mathrm{~nm}$. Moreover, the increase of hardness with increasing the indent depth was clearly observed within $\mathrm{h}<30 \mathrm{~nm}$, which are defined as an inverse ISE usually attributed to the surface effects. In order to eliminate the uncertainty driving from the complex 
indenter tip, the data within $50 \mathrm{~nm}$ were ignored in the following analysis and discussion in the present paper.
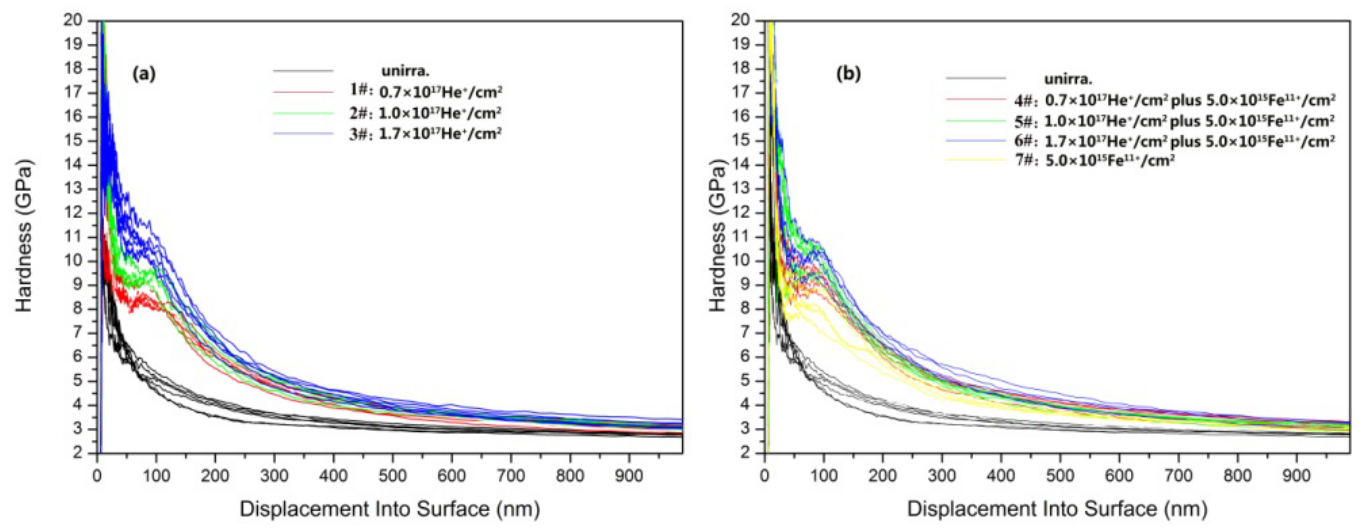

Fig. 2 The depth profiles of NI hardness in CLAM steel, un-irradiated samples denoted by Unirr. and samples irradiated under different conditions.
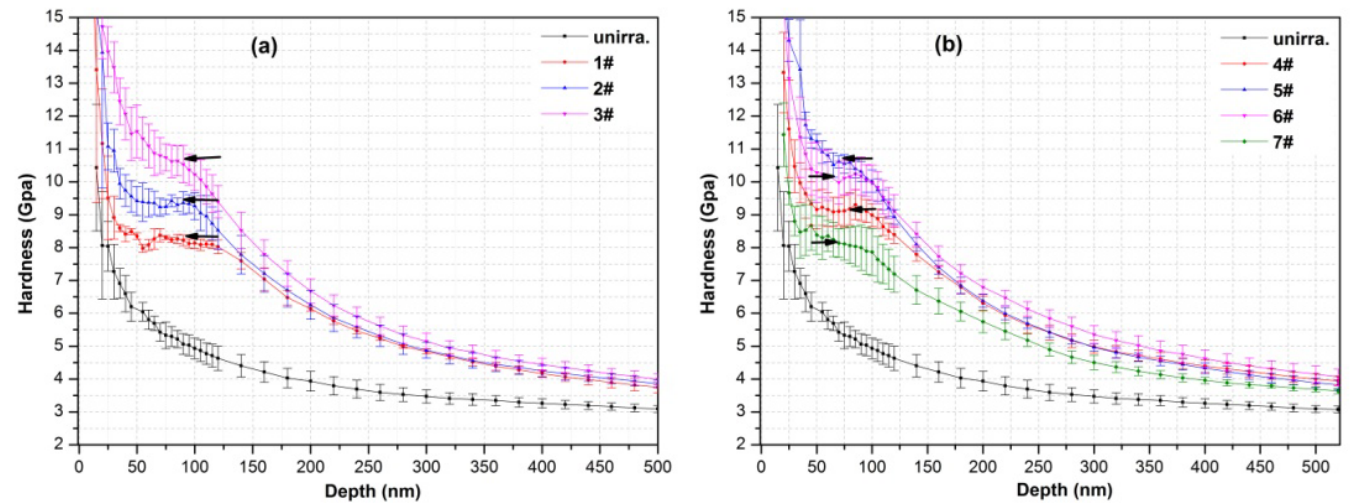

Fig. 3 Indentation depth of average nano-indentation hardness with error bar

The curve of average NI hardness against depth $\left(\mathrm{H}_{\mathrm{av}}-\mathrm{D}\right)$ for all the samples under different irradiation conditions is given in Fig. 3. It is clear that there is an evident hardening phenomenon after ions irradiation. The higher ion irradiation doses induce the greater the hardness. For the un-irradiated specimen, the $\mathrm{H}_{\mathrm{av}}^{\text {unirr. }}$-depth curve is asymptotic decreasing. In contrast, all the curves after $50 \mathrm{~nm}$ for the irradiated specimens can be roughly divided into two stages, namely the initial gentle drop (50-100 nm) and a relatively rapid decrease toward a nearly constant value as the penetration depth is beyond $\sim 500 \mathrm{~nm}$. All the curves of irradiated samples have an inflection at a critical depth $\left(\mathrm{h}_{\mathrm{c}}\right)$ of around $100 \mathrm{~nm}$ indicated by the arrows in Fig. 3. Fig. 4 shows $\mathrm{H}_{\mathrm{av}}^{\mathrm{irr}} / \mathrm{H}_{\mathrm{av}}^{\text {unirr. }}$ as a function of the indentation depth. There is a peak 
region around $100 \mathrm{~nm}$ in all of the curves which is consistent with the critical depth $\left(h_{c}\right)$ shown in Fig. 3. Over the critical depth, substrate soft effect (SSE) would take effect since the substrate began to plastic deformation even before indenter tip reaches the substrate. Therefore, the indentation depth range with little influence of soft substrate for all the specimens was determined to locate before $100 \mathrm{~nm}$. Then the $\mathrm{H}_{\mathrm{av}}^{\mathrm{irr}}$ decreased toward a nearly constant value as the penetration depth was beyond $\sim 500 \mathrm{~nm}$.
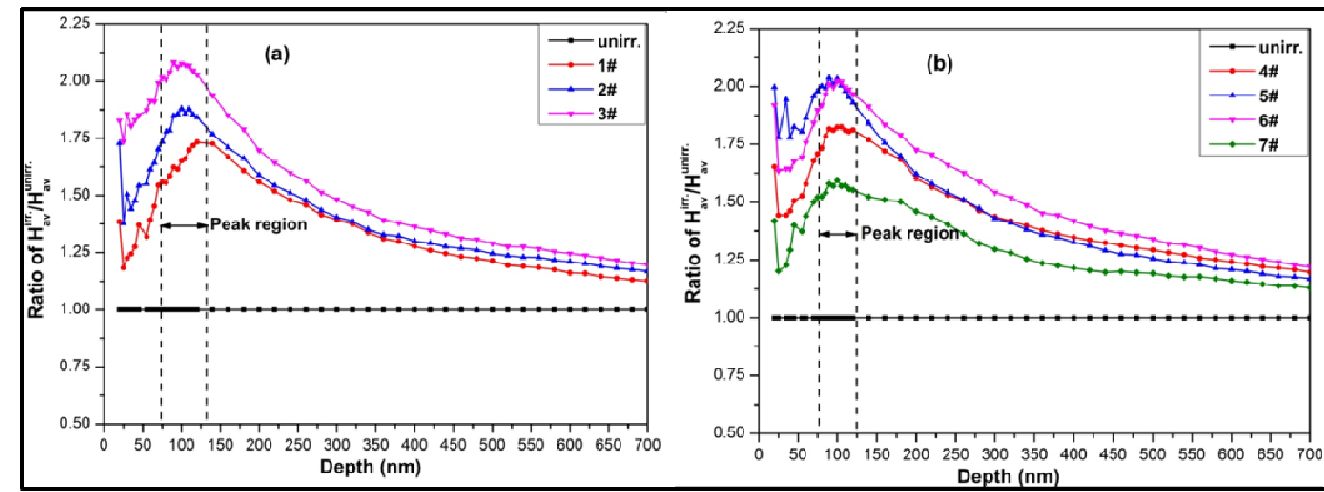

Fig. 4 Dependence of the ratio of $\mathrm{H}_{\mathrm{av}}^{\mathrm{irr}} / \mathrm{H}_{\mathrm{av}}^{\text {unirr. }}$ on indentation depth for the un-irradiated and irradiated samples.

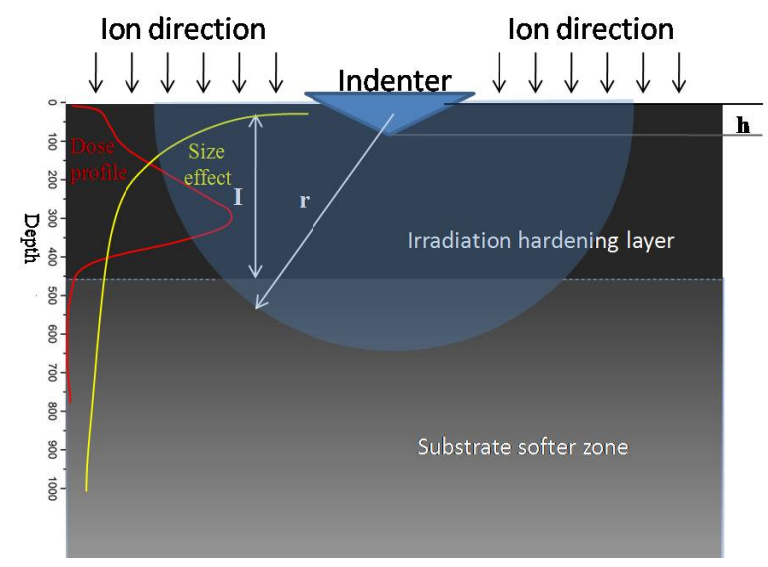

Fig. 5 Schematic diagram of nano-indentation process.

The depth profile of helium-ion irradiated sample is fairly complex ${ }^{[18]}$ which can be divided into three basic layers: the surface layer where the surface effect dominates, the second layer where the displacement damage and the helium-ion concentration are 
effective and the last layer is soft substrate. According to geometrically necessary dislocation model developed by Nix and Gao ${ }^{[19]}$, the influence zone under the indenter is hemispherical with a radius of about five times the indentation depth, which is the blue semicircle region in the schematic diagram as shown in Fig. $5^{\text {[20,21] }}$ Equation $(1)^{[22,23]}$ can be given as follows, where the percentage of affected soft substrate versus the total influence zone is calculated:

$$
\mathrm{V}_{\mathrm{h}}=\frac{\mathrm{g}^{2} \pi(3 \mathrm{r}-\mathrm{g})}{4 \pi \mathrm{r}^{3}}
$$

where $V_{h}$ is the volume fraction of softer substrate sampled at specific indentation depth, $r$ is the radius of the influence zone $(h * 5)$, and $g=5 h-t, h$ is the actual indention depth and $\mathrm{t}$ is the irradiation depth. Thus, $\mathrm{V}_{\mathrm{h}}$ is only $0.6 \%$ when $\mathrm{h}=\mathrm{h}_{\mathrm{c}}$, indicating indention depth before $h_{c}$ with little influence of the softer substrate. According to the above analysis, the nanoindentation data within the range of $50<\mathrm{h}$ $<100 \mathrm{~nm}$ is corresponding to the homogeneous hardening layer without the influence of substrate, which is a prerequisite to carry out the following analysis using Kasada method.

The indentation size effect for crystalline materials can be accurately modeled using the concept of geometrically necessary dislocations ${ }^{[19]}$, which is described by the well-known Nix-Gao model as the following equations:

$$
\mathrm{H}=\mathrm{H}_{0} \sqrt{1+\frac{\mathrm{h}^{*}}{\mathrm{~h}}}
$$

where $\mathrm{H}$ is the hardness for a given indentation depth $\mathrm{h}, \mathrm{H}_{0}$ the hardness at the infinite depth that can be referred to the bulk hardness, $h^{*}$ is a characteristic length that depends on the shape of the indenter, the shear modulus of indented material and $\mathrm{H}_{0}$. Fig. 6 gives the $\mathrm{H}^{2}-1 / \mathrm{h}$ plot of specimens irradiated under various conditions. It's clear that the data of un-irradiated specimen demonstrates a good linearity while the characteristic with approximate bi-linearity is present in the case of the irradiated samples in which the inflection point stands at about $100 \mathrm{~nm}$ indicated by a vertical black dotted line, which consists with the critical depth $\left(h_{c}\right)$ in Fig.3 and the peak region in Fig. 4. The nominal hardness $\mathrm{H}_{0}^{\text {irr. }}$ of the irradiated region can be obtained 
by fitting the corresponding data over the inflection point using Kasada method ${ }^{[24]}$. The results are given in Table 3 .
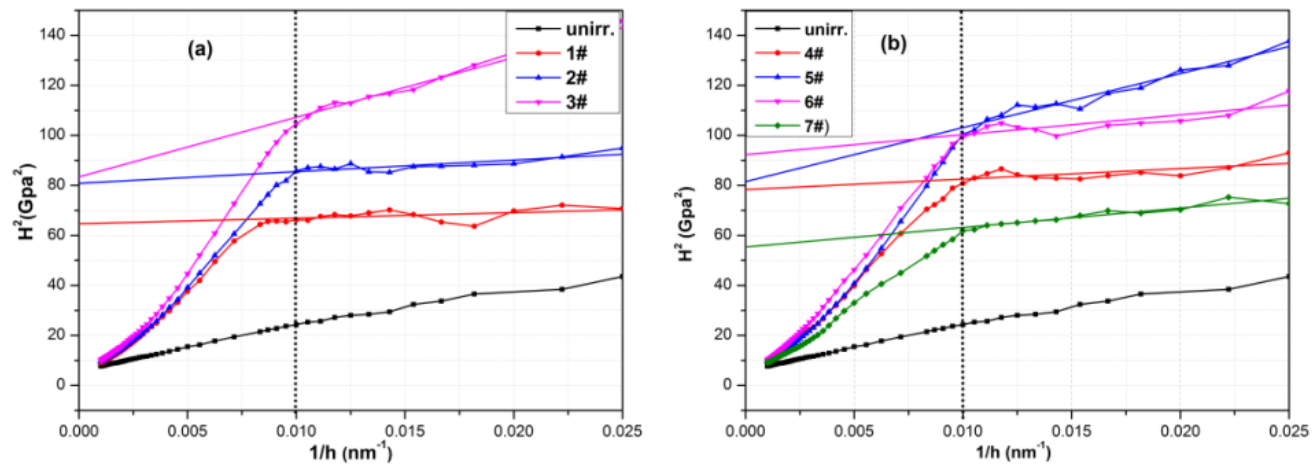

Fig. 6 Plots of $\mathrm{H}^{2}-1 / \mathrm{h}$ for average NI hardness of the un-irradiated sample and irradiated samples $(1 \#)(2 \#)(3 \#)(4 \#)(5 \#)(6 \#)(7 \#)$.

Table.3 Nominal hardness $\mathrm{H}_{0}$ based on Kasada method

\begin{tabular}{llllll}
\hline \multirow{2}{*}{} & \multirow{2}{*}{ Implanted He dose } & \multicolumn{4}{l}{ Irradiation condition } \\
\cline { 3 - 6 } & & unirradiated & $\mathrm{Fe}^{\mathrm{a}}$ single ion & He single ion & He and Fe ion \\
\hline Hardness(Gpa) & - & 2.73 & $7.44(7 \#)$ & - & - \\
Hardness(Gpa) & $0.7 \times 10^{17} \mathrm{He} / \mathrm{cm}^{2}$ & - & - & $8.04(1 \#)$ & $8.85(4 \#)$ \\
Hardness(Gpa) & $1.0 \times 10^{17} \mathrm{He} / \mathrm{cm}^{2}$ & - & - & $8.99(2 \#)$ & $9.02(5 \#)$ \\
Hardness(Gpa) & $1.7 \times 10^{17} \mathrm{He} / \mathrm{cm}^{2}$ & - & - & $9.13(3 \#)$ & $9.61(6 \#)$ \\
\hline
\end{tabular}

a The energy of $\mathrm{He}$ is $100 \mathrm{keV}$. Energy of $\mathrm{Fe}$ was chosen $950 \mathrm{keV}$ so that the $\mathrm{Fe}$ induced displacement profile overlap the He ion profile. The dose of $\mathrm{Fe}$ was chosen $5 \times 10^{15} \mathrm{Fe}^{11+} / \mathrm{cm}^{2}$.

The $\mathrm{H}_{0}^{\mathrm{irr} .}$ of un-irradiated CLAM steel is obtained to be $2.73 \mathrm{GPa}$. For the specimens irradiated with single- and Sequential dual-ion at room temperature, evident irradiation hardening can be observed in all samples and it increased with increasing the $\mathrm{He}^{+}$dose. The hardness reaches $8.04 \mathrm{GPa}, 8.99 \mathrm{GPa}$ and $9.13 \mathrm{GPa}$ for single-He implanted samples 1\#, 2\#, 3\#, respectively; and goes to $8.85 \mathrm{GPa}, 9.02 \mathrm{GPa}$, 9.61 GPa for the dual-ion irradiated samples 4\#, 5\#, 6\#, respectively. Note that the irradiation hardening for the sample with Fe-ion implantation (7\#) is less than that of helium-ion irradiation (1\#). The reason can be analyzed in the following microstructure evolution observation.

Compared the hardness for samples irradiated between single helium and Sequential dual-ion (helium- plus iron-ions) irradiated samples, it seems that the subsequent irradiation of heavy $\mathrm{Fe}$ ions does not have significant effect on the hardness increment. So, the Sequential dual-ion irradiation hardening is not the simple 
superposition of every hardness induced by single-ion irradiation. Defects recombination and changes in the defect characteristics such as the size and density may be the main reasons due to the distinct synergistic effect of helium and subsequent $\mathrm{Fe}$ ions irradiation, which was explored by the following microstructure analysis.

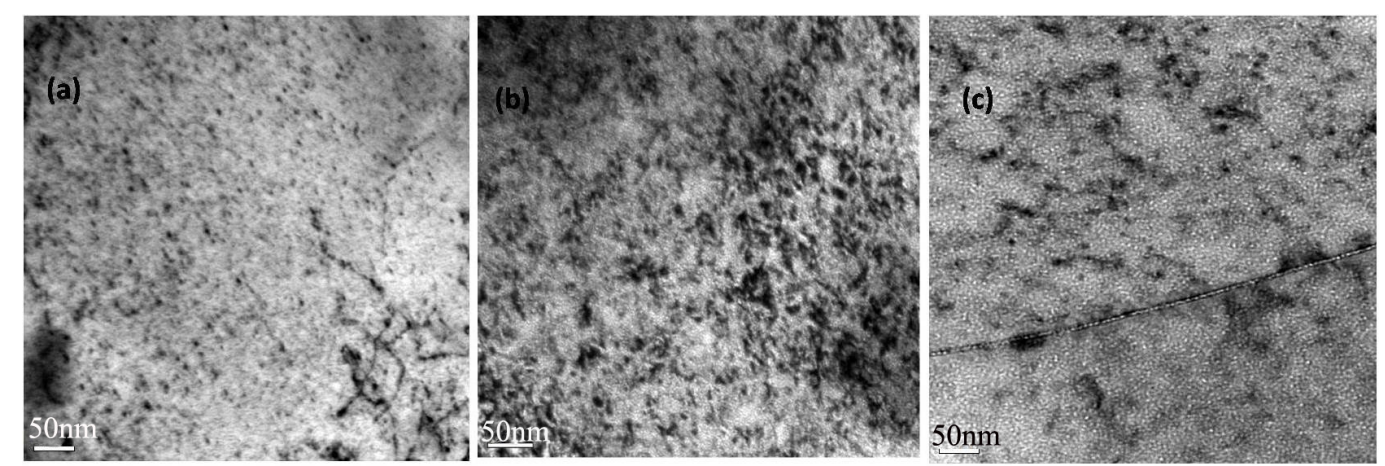

Fig. 7 Microstructure of CLAM steel irradiated with $100 \mathrm{keV} \mathrm{He}{ }^{+}$ions.(a) $0.7 \times 10^{17} \mathrm{He}^{+} / \mathrm{cm}^{2}$ (b) $1.0 \times 10^{17} \mathrm{He}^{+} / \mathrm{cm}^{2}$ (c) $1.7 \times 10^{17} \mathrm{He}^{+} / \mathrm{cm}^{2}$.

To understand the NI hardness results thus further explain the synergistic effect of helium and Fe ions, corresponding microstructure analysis was carried out by advanced transmission electron microscopy. Fig. 7 shows the related micrographs of specimens irradiated by single $\mathrm{He}^{+}$with different doses. At low helium dose level $\left(0.7 \times 10^{17} \mathrm{ion} / \mathrm{cm}^{2}\right)$, black dots like defect clusters were observed without the detection of bubbles, as shown in Fig. 7a. Around the dose of $1.0 \times 10^{17} \mathrm{He}^{+} / \mathrm{cm}^{2}$, fine bubbles with high density can be clearly resolved and verified by over focused and under focused contrast shown in Fig. 7b. So the helium dose for helium bubbles beginning to grow up that can be clearly resolved by TEM is then determined to be around $0.7 \times 10^{17} \sim 1.0 \times 10^{17} \mathrm{He}^{+} / \mathrm{cm}^{2}$ under single $100 \mathrm{keV} \mathrm{He}^{+}$irradiation at room temperature. It should be noted that sub-microscopic bubbles may be formed at much lower doses which can not be distinguished very well considering the resolution of TEM. The atomistic behavior of helium as well as the nucleation and growth of helium bubbles are briefly surveyed by Ullmaier ${ }^{[25]}$. Furthermore, helium bubbles gathered at grain boundaries was found in Fig. $7 \mathrm{c}$ as the dose increased to $1.7 \times 10^{17}$ $\mathrm{He}^{+} / \mathrm{cm}^{2}$. The bubble size and number density increased gradually with the increase of 
dose, which were statistically determined to be $1.61 \pm 0.13 \mathrm{~nm}, 3.32 \times 10^{23} / \mathrm{m}^{3}$ and $1.95 \pm 0.12 \mathrm{~nm}, 5.27 \times 10^{23} / \mathrm{m}^{3}$, respectively for the samples irradiated with $1.0 \times 10^{17}$ $\mathrm{He}^{+} / \mathrm{cm}^{2}$ and $1.7 \times 10^{17} \mathrm{He}^{+} / \mathrm{cm}^{2}$.

Within the series of dose range, the main contribution to hardening may change from two separate pin centers: defect clusters and helium filled bubbles. When the ion implantation dose is relatively low, such as around $0.7 \times 10^{17} \mathrm{He}^{+} / \mathrm{cm}^{2}$ in the present study, the ion-induced small defects/defect clusters would be the main pin centers and impede the dislocation motion (Fig. 7a). With the increase of dose, defects and bubbles may coexist and work together contributing to the irradiation hardening (Fig. $7 \mathrm{~b}$ ). And then, bubbles become the dominant factor to hinder the dislocation motion when the $\mathrm{He}^{+}$dose reaches higher one, say $1.7 \times 10^{17} \mathrm{He}^{+} / \mathrm{cm}^{2}$ here (Fig. 7c). The bubble nuclei form continuously when the samples undergo $\mathrm{He}^{+}$irradiation resulting in the increase of number density.

For comparison, the helium bubble micrographs evolution of specimens irradiated with Sequential dual ions $\left(\mathrm{He}^{+}\right.$plus $\left.\mathrm{Fe}^{11+}\right)$ has been investigated and the results are given in Fig. 8. Distinctly, a large number of helium bubbles with small sizes has formed in the Sequential dual-ion irradiated samples even with the lowest dose of $0.7 \times 10^{17} \mathrm{He}^{+} / \mathrm{cm}^{2}$ (Fig. 8a). This is quite different from the situation under single $\mathrm{He}^{+}$implantation with the same dose in which no helium bubble was found (Fig. 7a ). The bubbles grow up while number density decreased after iron-ion irradiation, as shown in Figs. 8(b,c) and Fig.7(b,c). The statistical analysis for sequential dual-ion irradiation samples were conducted, with size and number density of $5.8 \mathrm{~nm}, 0.77 \times 10^{22} / \mathrm{m}^{3} ; 6.4 \mathrm{~nm}, 1.38 \times 10^{22} / \mathrm{m}^{3} ; 10.2 \mathrm{~nm}, 1.14 \times 10^{22} / \mathrm{m}^{3}$ for Fig.(a), (b), (c) respectively. It reveals that the subsequent irradiation of Fe-ions greatly promoted the aggregation and growth of helium bubbles. 

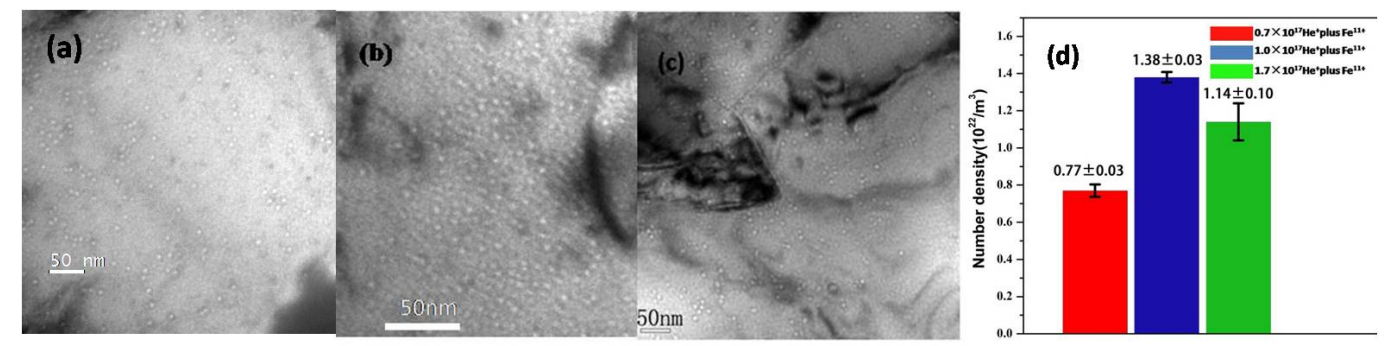

Fig. 8 TEM micrographs of helium bubbles for CLAM steel irradiated with $100 \mathrm{keV} \mathrm{He}{ }^{+}$ $+950 \mathrm{keV} \mathrm{Fe}^{11+}$ at room temperature.(a) $0.7 \times 10^{17} \mathrm{He}^{+} / \mathrm{cm}^{2}+5 \times 10^{15} \mathrm{Fe}^{11+} / \mathrm{cm}^{2}$, (b) $1.0 \times 10^{17}$ $\mathrm{He}^{+} / \mathrm{cm}^{2}+5 \times 10^{15} \mathrm{Fe}^{11+} / \mathrm{cm}^{2},(\mathrm{c}) 1.7 \times 10^{17} \mathrm{He}^{+} / \mathrm{cm}^{2}+5 \times 10^{15} \mathrm{Fe}^{11+} / \mathrm{cm}^{2}$, (d) the statistical results of number density of helium bubbles with error bar.

The synergistic interaction of pre-implanted helium, subsequent self-ion iron and the irradiation-induced defects may significantly affect the evolution of helium bubbles. Some studies focused on the He behaviors in $\mathrm{W}$ by molecular dynamics method suggested that the formation and initial growth mechanism of helium bubbles were based on the procedure of He-Vacancy cluster formation, the capturing of vacancies and then $\mathrm{He}$ atoms, and vacancies again ${ }^{[26]}$. The formation and initial growth behavior of helium bubbles are supposed to be the same in all body-centred cube materials. On one hand, the implantation of helium ions may induce a great number of defects in materials such as interstitial atoms (I) and vacancies (V). Interstitial atom clusters (Is) and vacancy clusters (Vs) would then develop followed by dislocation loops or voids due to the interaction of the single point defects and cascade effect during next irradiation process. Then helium bubbles would form and grow up by capturing vacancies and helium atoms. On the other hand, cascade may induce the resolution of $\mathrm{He}$ atoms from small $\mathrm{nm}$-size bubbles during the following $\mathrm{Fe}^{11+}$ irradiation, meaning that helium atoms can be removed from bubbles and return to the material matrix by direct collisions between energetic particles and helium atoms ${ }^{[27,28]}$. During the $\mathrm{Fe}^{11+}$ irradiation, the helium resolution effect was more noticeable in the samples with higher dose pre-implanted helium. Helium atoms removed from small bubbles due to the iron ions energetic recoil may be absorbed by the adjacent large bubbles resulting in the shrinkage of small bubbles and the growth of large bubbles. Thus small bubbles disappeared and the density of bubbles decreased gradually. 


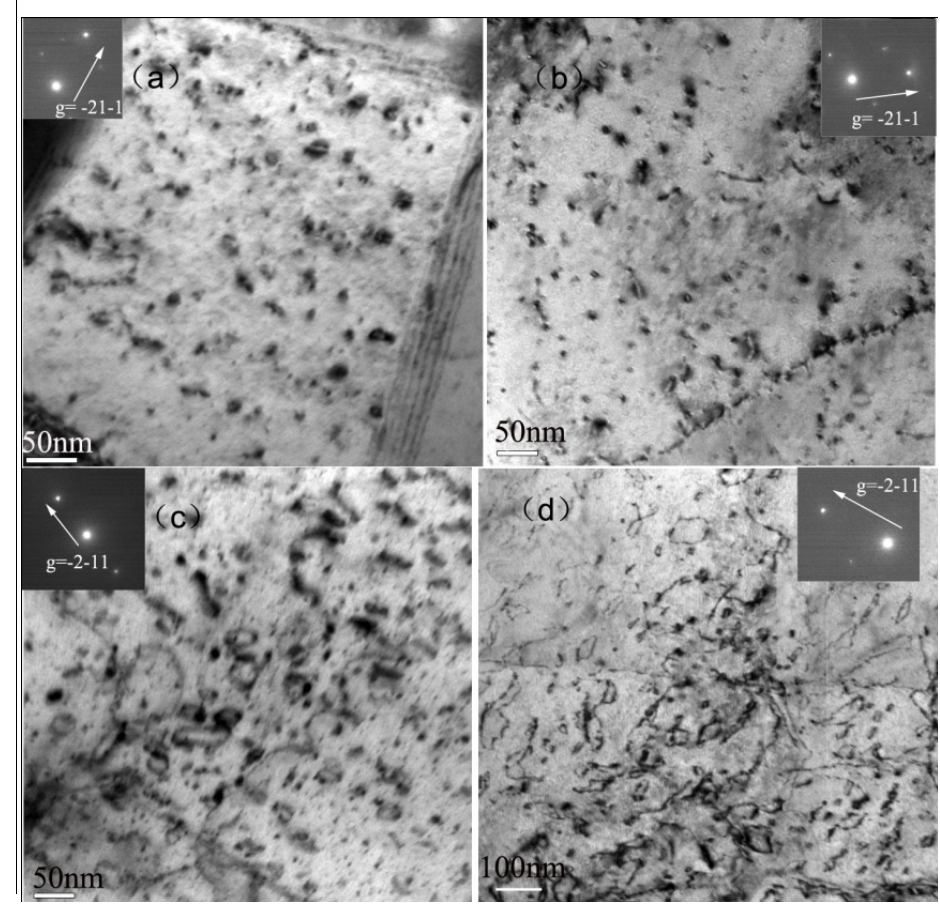

Fig. 9 TEM micrographs of dislocation loops for CLAM steel irradiated with single $950 \mathrm{keV}$ $\mathrm{Fe}^{11+}$ and 100keV $\mathrm{He}^{+}+950 \mathrm{keV} \mathrm{Fe}^{11+}$ at room temperature. (a) $5 \times 10^{15} \mathrm{Fe}^{11+} / \mathrm{cm}^{2}$, (b) $0.7 \times 10^{17}$ $\mathrm{He}^{+} / \mathrm{cm}^{2}+5 \times 10^{15} \mathrm{Fe}^{11+} / \mathrm{cm}^{2}$, (c) $1.0 \times 10^{17} \mathrm{He}^{+} / \mathrm{cm}^{2}+5 \times 10^{15} \mathrm{Fe}^{11+} / \mathrm{cm}^{2}$, (d) $1.7 \times 10^{17} \mathrm{He}^{+} / \mathrm{cm}^{2}+$ $5 \times 10^{15} \mathrm{Fe}^{11+} / \mathrm{cm}^{2}$.

Fig. 9 gives the micrographs of dislocation loops at the diffraction vector of $\mathrm{g}=\overline{2} \overline{1} 1$. It's clear that Fe ions irradiation produced damage in large dislocation loops compared with the fine dislocation loops with high density present in helium ion irradiated one (Fig. 7a). Therefore, it can be qualitatively explained that the irradiation hardening for the sample with Fe-ion implantation (7\#) is less than that of helium-ion irradiation (1\#) since the irradiation hardening is proportional to the square root of the product of size and density according to the theory of dispersed barrier hardness ${ }^{[29]}$. No distinct voids were observed in the Fe-ion irradiated sample. On the other hand, distinct increase on the size of dislocation loops could be observed in the Sequential dual-ion irradiated samples. With the increase of helium dose and subsequent iron-ion dose keeping the constant, the size of dislocation loops in diameter goes to about 16.1 $\mathrm{nm}, 27.7 \mathrm{~nm}, 52.3 \mathrm{~nm}$; the number densities are about $7.1 \times 10^{21} / \mathrm{m}^{3}, 4.68 \times 10^{21} / \mathrm{m}^{3}$, $2.64 \times 10^{21} / \mathrm{m}^{3}$, respectively, as shown in Fig. 9 (b, c, d). It is clear that the number density of dislocation loops decreased while the size expanded with the increase of helium dose in the sequential helium and iron ions irradiated samples. 
During the irradiation process with heavy self-ion (Fe-ion), abundant vacancies and interstitial atoms were produced and the number of interstitial atoms increased a lot. For helium pre-implanted samples, as mentioned before, the pre-generated V-He clusters as strong sinks for vacancies may trap a large number of vacancies resulting in the defects recombination. The higher concentration of helium, the more traps for absorbing vacancies, then the more survival probability of interstitials. In addition, the strong ability of diffusion for interstitial atoms makes it be absorbed easily by self interstitial atom (SIA) type of dislocation loops. Hence, residual interstitial atoms are absorbed by SIA type loops more and more, which promote the size increase of dislocation loops. On the other hand, the existed small defects induced by helium-ion irradiation would diffuse and merge together during the subsequent high energy Fe-ion irradiation, resulting in the growth of dislocation loops and the decrease of number density with increasing the irradiation dose in sequential dual-ion irradiated samples. It's known that the irradiation hardening is proportional to the square root of the product of size and density according to the theory of dispersed barrier hardness ${ }^{[29]}$. So the increased size and decreased number density in sequential dual-ion irradiated samples would qualitatively explain the result that the irradiation of Fe-ions does not have significant effect on the hardness increment.

It is well established that dislocation loops and bubbles are assumed to act as barriers to gliding dislocations in the slip plane and impede their movements, therefore resulting in radiation hardening ${ }^{[30]}$. The dispersed barrier model (Eq.(2)) is most appropriate for strong obstacles, such as dislocation loops. The FKH model (Eq.(3)) was developed by Friedel-Kroupa-Hirsch (FKH) for weak obstacles, such as helium bubbles ${ }^{[31,32]}$. The irradiation hardening could be calculated based on the microstructure feature and dispersion barrier hardening model ${ }^{[29]}$, which describes the flow stress required to sustain plastic deformation

$$
\begin{aligned}
& \Delta \sigma_{\mathrm{y}}=\mathrm{M} \cdot \alpha \cdot \mu \cdot \mathrm{b}(\mathrm{Nd})^{1 / 2} \\
& \Delta \sigma_{\mathrm{y}}=\frac{1}{8} \mathrm{M} \cdot \mu \cdot \mathrm{b} \cdot \mathrm{d} \cdot \mathrm{N}^{2 / 3} \\
& \Delta \mathrm{H} \cong 3 \Delta \sigma_{\mathrm{y}}
\end{aligned}
$$


where $M$ is the averaged Taylor factor for a BCC polycrystal in tension $(\mathrm{M} \approx 3), \alpha$ is the barrier strength $\mu \approx 84 \mathrm{GPa}$ is shear modulus of matrix. The Burger's vector magnitude (b) of the moving dislocation is about $0.26 \mathrm{~nm}, \mathrm{~N}$ is the obstacle number density, $\mathrm{d}$ is the obstacle diameter. $\Delta \sigma_{\mathrm{y}}$ is yield stress and $\Delta \mathrm{H}$ is hardening increment. Considering the typical strength of dislocation loops, $\alpha$ is taken as 0.45 in BCC materials expressed in Eq. $(2)^{[33]}$. Therefore, the contribution from dislocation loops on the increase in yield stress can be obtained to be $0.315 \mathrm{GPa}, 0.335 \mathrm{GPa}$, $0.346 \mathrm{GPa}$, corresponding increase of hardness $0.945 \mathrm{GPa}, 1.005 \mathrm{GPa}, 1.038 \mathrm{GPa}$. On the other hand, the hardening relationship for weak obstacles such as helium bubbles $^{[34]}$ is developed by Friedel-Kroupa-Hirsch (Eq.(3)). Thus, the increase in yield stress $\Delta \sigma_{\mathrm{y}}$ induced by helium bubbles can be calculated to be $0.018 \mathrm{GPa}, 0.031$ GPa, $0.042 \mathrm{GPa}$., corresponding increase of hardness $0.055 \mathrm{GPa}, 0.092 \mathrm{GPa}, 0.127$ GPa for Fig8. (a), (b), (c) respectively. Therefore, we can sum $\Delta \mathrm{H}$ from each type of defects. The total hardness increment of the dual-ion irradiated samples was $1.0 \mathrm{GPa}$, 1.097 $\mathrm{GPa}$ and $1.165 \mathrm{GPa}$ for the ion dose of $0.7 \times 10^{17} \mathrm{He}^{+} / \mathrm{cm}^{2}+5 \times 10^{15} \mathrm{Fe}^{11+} / \mathrm{cm}^{2}$, $1.0 \times 10^{17} \mathrm{He}^{+} / \mathrm{cm}^{2}+5 \times 10^{15} \mathrm{Fe}^{11+} / \mathrm{cm}^{2}, 1.7 \times 10^{17} \quad \mathrm{He}^{+} / \mathrm{cm}^{2}+5 \times 10^{15} \mathrm{Fe}^{11+} / \mathrm{cm}^{2}$,

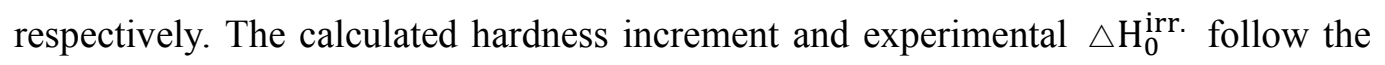
same trend that the hardening increment increased with helium dose. It should be noted that the calculated $\Delta \mathrm{H}$ is very small comparing to experimental values which is reasonable considering the complex experimental conditions, such as the different areas where obtained the hardness between the NI tests and TEM observations, the measurement errors in the number density and size of dislocation loops due to the complex diffraction contrast.

\section{Conclusions}

Single $\mathrm{He}^{+}$and dual-( $\mathrm{He}^{+}$plus $\mathrm{Fe}^{11+}$ subsequently) ions irradiations were performed to CLAM steel at room temperature and irradiation hardening and microstructure evolutions are evaluated by nano-indentation test and TEM analysis. 
The helium dose forming observed bubbles resolved by TEM clearly in CLAM steel was found to be $0.7 \times 10^{17} \sim 1.0 \times 10^{17} \mathrm{He}^{+} / \mathrm{cm}^{2}$ under single $100 \mathrm{keV} \mathrm{He}{ }^{+}$irradiation at room temperature. The hardening increase was in positive correlation to helium dose, which is probably because that defects density and size increased with helium dose, which act as barriers to the movement of dislocations movements.

Under Sequential dual-ion irradiation, subsequently self-ion $\mathrm{Fe}^{11+}$ with high energy can strongly promote the expansion of dislocation loops and the evolution of helium bubbles. However, there is no significant increase on the irradiation hardening in the sequential-ions irradiated samples compared with single helium irradiated ones due to the synergistic effect of helium and subsequent iron ions irradiation which resulted in the defects density decreased while size increased.

Moreover, the increase of hardness of dual-ion irradiated samples was calculated based on the microstructure analysis and dispersion strengthening model. Though the calculated value is much smaller than the experimental ones, they all follow the same trend that the hardness increase is in proportion to the helium dose.

\section{Acknowledgements}

This work was supported by the National Magnetic Fusion Program (Grant Nos. 2011GB108002, 2014GB104003, 2014GB120001) and the National Science Foundation of China with Grant Nos. 51571021, 51371031.

\section{Reference:}

[1] Proust E, Anzidei L, Casini G, Dalle Donne M, Giancarli L, Malang S. Breeding blanket for DEMO. Fusion engineering and design 1993;22:19-33.

[2] Trinkaus $H$, Singh BN. Helium accumulation in metals during irradiation - where do we stand? Journal of Nuclear Materials 2003;323:229-42.

[3] Zhang H, Ren F, Wang Y, Hong M, Xiao X, Qin W, et al. In situ TEM observation of helium bubble evolution in V/Ag multilayer during annealing. Journal of Nuclear Materials 2015;467:537-43.

[4] Lee J, Kasada R, Cho H, Kimura A. Irradiation-induced hardening and embrittlement of high-Cr ODS ferritic steels. Effects of Radiation on Nuclear Materials and the Nuclear Fuel Cycle: 24th Volume: ASTM International; 2010.

[5] Fu Z, Liu P, Wan F, Zhan Q. Helium and hydrogen irradiation induced hardening in CLAM steel. 
Fusion Engineering and Design 2015;91:73-8.

[6] Halliday F, Armstrong DE, Murphy JD, Roberts SG. Nanoindentation and micromechanical testing of iron-chromium alloys implanted with iron ions. Advanced Materials Research: Trans Tech Publ; 2009. p. 304-7.

[7] Lewis M, Packan N, Wells G, Buhl R. Improved techniques for heavy-ion simulation of neutron radiation damage. Nuclear Instruments and Methods 1979;167:233-47.

[8] Ziegler JF, Biersack JP. The stopping and range of ions in matter: Springer; 1985.

[9] Shin C, Jin H-h, Kim M-W. Evaluation of the depth-dependent yield strength of a nanoindented ion-irradiated $\mathrm{Fe}-\mathrm{Cr}$ model alloy by using a finite element modeling. Journal of Nuclear Materials 2009;392:476-81.

[10] Li X, Bhushan B. A review of nanoindentation continuous stiffness measurement technique and its applications. Materials characterization 2002;48:11-36.

[11] Nix WD, Gao H. Indentation size effects in crystalline materials: a law for strain gradient plasticity. Journal of the Mechanics and Physics of Solids 1998;46:411-25.

[12] Kasada R, Takayama Y, Yabuuchi K, Kimura A. A new approach to evaluate irradiation hardening of ion-irradiated ferritic alloys by nano-indentation techniques. Fusion Engineering \& Design 2011;86:2658-61.

[13] Liu P, Wan F, Zhan Q. A model to evaluate the nano-indentation hardness of ion-irradiated materials. Nuclear Instruments and Methods in Physics Research Section B: Beam Interactions with Materials and Atoms 2015;342:13-8.

[14] Liu P, Zhao M, Zhu Y, Bai J, Wan F, Zhan Q. Effects of carbide precipitate on the mechanical properties and irradiation behavior of the low activation martensitic steel. Journal of Alloys and Compounds 2013;579:599-605.

[15] Ge H, Peng L, Dai Y, Huang Q, Ye M. Tensile properties of CLAM steel irradiated up to $20.1 \mathrm{dpa}$ in STIP-V. Journal of Nuclear Materials 2016;468:240-5.

[16] Huang Q. Development status of CLAM steel for fusion application. Journal of Nuclear Materials 2014;455:649-54.

[17] Norgett M, Robinson M, Torrens I. A proposed method of calculating displacement dose rates. Nuclear Engineering and Design 1975;33:50-4.

[18] Liu P, Zhan Q, Fu Z, Wei Y, Wang Y, Wang F, et al. Surface and internal microstructure damage of He-ion-irradiated CLAM steel studied by cross-sectional transmission electron microscopy. Journal of Alloys and Compounds 2015;649:859-64.

[19] Nix William D, Gao H. Indentation size effects in crystalline materials: A law for strain gradient plasticity. Journal of the Mechanicss\&sphysics of Solids 1998;46:411-25.

[20] Katoh Y, Ando M, Kohyama A. Radiation and helium effects on microstructures, nano-indentation properties and deformation behavior in ferrous alloys. Journal of nuclear materials 2003;323:251-62.

[21] Kiener D, Pippan R, Motz C, Kreuzer H. Microstructural evolution of the deformed volume beneath microindents in tungsten and copper. Acta Materialia 2006;54:2801-11.

[22] Korsunsky A, McGurk M, Bull S, Page T. On the hardness of coated systems. Surface and Coatings Technology 1998;99:171-83.

[23] Hosemann P, Kiener D, Wang Y, Maloy SA. Issues to consider using nano indentation on shallow ion beam irradiated materials. Journal of Nuclear Materials 2012;425:136-9.

[24] Kasada R, Takayama Y, Yabuuchi K, Kimura A. A new approach to evaluate irradiation hardening of ion-irradiated ferritic alloys by nano-indentation techniques. Fusion Engineering and Design 
2011;86:2658-61.

[25] H.Ullmaier. The influence of helium on the bulk properties of fusion reactor structural materials. Nucl Fusion 1984;24

[26] Li X-C, Liu Y-N, Yu Y, Luo G-N, Shu X, Lu G-H. Helium defects interactions and mechanism of helium bubble growth in tungsten: A molecular dynamics simulation. Journal of Nuclear Materials 2014;451:356-60.

[27] Parfitt DC, Grimes RW. Predicted mechanisms for radiation enhanced helium resolution in uranium dioxide. Journal of Nuclear Materials 2008;381:216-22.

[28] Trinkaus $\mathrm{H}$. The effect of cascade induced gas resolution on bubble formation in metals. Journal of Nuclear Materials 2003;318:234-40.

[29] Lucas GE. The Evolution Of Mechanical Property Change In Irradiated Austenitic Stainless Steels. Journal of Nuclear Materials 1993;206:287-305.

[30] Was GS. Fundamentals of radiation materials science: metals and alloys: Springer Science \& Business Media; 2007.

[31] Friedel J. Dislocations Pergamon Press 1964.

[32] F. Kroupa PBH. Disc Faraday Soc 1964;38 49.

[33] Ohr SM, Wechsler MS, Chen CW, Hinkle NE. Radiation hardening and radiation-anneal hardening in body-centered cubic metals. pp 742-6 of Second International Conference on the Strength of Metals and Alloys, Pacific Grove, California, 30 August--4 September 1970 Vol II Metals Park, Ohio American Society for Metals.

[34] Zinkle SJ, Matsukawa Y. Observation and analysis of defect cluster production and interactions with dislocations. Journal of nuclear materials 2004;329:88-96. 